\title{
Dossiê
}

REsumo
A partir do enigma colocado
pelo autismo, o presente traba-
lho analisa a entrada do bebê
na linguagem, as vicissitudes
da incorporação da voz e sua
operação enquanto objeto pul-
sional. Consideramos o manhês
e a lalação como fenômenos em
que a função sonora e a função
significante da voz operam para
articular o encontro entre o real
do corpo do infans com o simbó-
lico da linguagem. Demarcamos
que não bá uma ordem instintiva
ou natural para a entrada na
linguagem, que a palavra é
algo estrangeiro ao neonato.
Consideramos tais elaboraçôes
fundamentais para direcionar o
trabalho clinico com o autismo.
Des critores: psicanálise;
autismo; linguagem; voz:

\section{AUTISMO E OS \\ PRIMÓRDIOS DA \\ PALAVRA: PULSÃO \\ INVOCANTE, CORPO E LINGUAGEM}

Aline Alves da Silva Travaglia

DOI: http://dx.doi.org/xx.xxxxx/issn.xxxx-xxxx.v19i2p263-276

Uma palavra está nascendo

Na boca de uma criança:

Mais atrasada do que um murmúrio.

Não tem história nem letras -

Está entre o coaxo e o arrulho.

(Manoel de Barros)<smiles>c1ccccc1</smiles>

presente artigo tem como objetivo tratar da ligação primordial que o filhote humano faz com a linguagem; como é necessário que a palavra se assimile ao vivente para tornar o ser da necessidade um sujeito do desejo. Diante do autismo partimos para pensar não apenas como essa forma de existência se dá, mas, fundamentalmente,

Mestranda do Programa de Pós-graduação em Psicologia Social da Pontifícia Universidade Católica de São Paulo (PUC-SP). Bolsista do Conselho Nacional de Desenvolvimento

Científico e Tecnológico. 
como a linguagem habita o humano e faz nele uma suprassunção da natureza. Neste trajeto de análise, nos inspiramos majoritariamente nos trabalhos de Inês Catão (2009) e Marie Cristine Laznik (Laznik, Maestro, Muratori \& Parlato-Oliveira, 2006) que tratam a questão do autismo com ênfase no objeto voz.

Analisaremos adiante o fenômeno da incorporação do significante ao real com o momento no qual a palavra se articula com o organismo - ponto crucial que faz do humano um animal falante, um ser de linguagem. Elaboraremos o momento primevo, quando o bebê está diante de um mar de significantes, mas ainda não assimilou a linguagem em sua complexidade. Partiremos para pensar como se dá essa assimilação e como que, da linguagem incorporada, pode brotar o sujeito. Os fenômenos do manhês e da lalação nos servem como base da protoconversação em que a voz opera convocando o infans, e este, atravessado pelo desejo do Outro, pode assumir seus próprios sons construindo sua voz para, futuramente, falar.

Há um momento mítico da articulação do significante com o organismo (Catão, 2009), momento que a linguagem começa a tocar o corpo para fazer sua marca fundante. Para alguns psicanalistas, principalmente os que estudam o autismo (Catão, 2009; Laznik, Maestro, Muratori, \& Parlato-Oliveira, 2006; Vorcaro, 2004), essa incorporação do significante se dá por mediação da voz; não que a linguagem seja vocalização, como alerta Lacan (2005, p.299), mas que há algo na pulsão invocante que ativa a cadeia significante no processo de formação do sujeito. Didier-Weill (1998) fala do real do corpo da criança como uma espécie de ardósia mágica na qual vai se inscrever algo da ordem do simbólico, e esta articulação forma o traço no qual despontará o sujeito. Essa inscrição do simbólico no corpo formando um "corpolinguagem" é presidida pela voz e suas modulações sonoras.

Em suas protoconversaçôes, mãe e criança partilham a voz, que dá suporte ao que se constituirá como corpolinguagem. $\mathrm{O}$ ato de endereçamento do Outro materno inscreve no corpo do infans, sob a forma de letra, o que a voz porta de enigmático do desejo do Outro (Catão, 2009, p. 188).

No momento do manhês uma mensagem de "pura significância" (Laznik, 2004) é endereçada ao infans, mensagem cujo conteúdo explícito é desimportante em relação à forma como é emitida. A entonação e os picos prosódicos do som da voz do adulto têm a função de seduzir a criança, como o canto da sereia (Catão, 2009).

264 Estilos clin., São Paulo, v. 19, n. 2, mai./ago. 2014, 263-276. 
Essa prosódia é conhecida como manhês, mas não fica reduzida à posição materna ${ }^{1}$. A função sonora da voz se faz predominante nos tempos iniciais. O bebê, se deixando levar pela prosódia da voz do Outro primordial, inicia o processo de se alienar nos significantes que esse Outro fornece.

Quanto a esse momento de articulação entre simbólico e real, Catão diz que: "antes de receber a palavra o sujeito recebe previamente a raiz onde esta germinará" (2009, p. 169). Essa raiz, anterior à palavra, seria a música, a voz em sua função sonora, melódica, harmônica e rítmica. Com o poder musical da voz se abriria caminho para vir a palavra, os significantes, a linguagem. Completamos essa ideia dizendo que, se a música é a raiz da palavra, é no gérmen da palavra que poderá brotar um sujeito.

Portanto, a palavra é a raiz, a semente, o princípio, e não em um sentido metafísico, mas sim no princípio material. A palavra não se autoengendra no infans, nem é criada $e x$ nibilo. Como semente, a palavra vem do outro, transporta um fragmento do que há numa floresta de significantes e funda um novo falante da língua a partir desse fragmento que lhe marca o corpo.

\section{O manhês}

Os adultos cercam a criança de sons e usam a musicalidade das palavras para chamar sua atenção. A criança, a partir dessa sedução, se deixaria alienar no chamado que ela nem sabe ainda ao que a convida, e assim brota em seu corpo, não sem algum espanto, os primeiros barulhos votados à alteridade, o som sai de sua dimensão puramente real e começa a perfazer as possibilidades de um endereçamento no balbuciar.

Ainda não há um sujeito constituído no bebê, porém, pressupor que na criança haverá um sujeito é a condição de possibilidade para que um dia haja. Com a fala do manhês se pode tomar o infans como um interlocutor e convocá-lo para a linguagem antecipando sua posição de falante. "Esta subjetividade antecipada pela mãe faz do bebê um interlocutor desde as protoconversações" (Campanário, 2008, p. 94) e é emprestando-lhe voz que um dia ele assumirá uma posição no ato de fala. Testemunhamos que no autismo é essa posição de assunção enquanto falante que não se opera. A criança autista, mesmo que emita seus enunciados, não assume a posição de enunciação, de sujeito do inconsciente.

O chamado endereçado ao bebê é o que o convida a alienar-se à linguagem preparando o sujeito do inconsciente. Lacan coloca como S esse sujeito que pressupomos haver na criança, como $S$ primordial, sem barra e sem índice. Esse $\mathrm{S}$ primordial, sujeito pressuposto no infans, "primeiro ele ouve um "tu és" sem atributo" (Lacan, 2005, p.297). Este Tu és imperativo 
constitui-se como resposta à pergunta do pequeno ser, pergunta essa que o bebê não articula, mas que no nível do inconsciente diria: "quem sou eu?".

Acreditamos que o manhês seja a via por onde passa essa mensagem de pura significância, mensagem que diz ao S o "tu és" sem lhe atribuir algo; construção necessária para responder uma pergunta que não foi feita, mas que deve existir como pressuposto lógico na constituição subjetiva.

"Os primeiros intercâmbios sonoros já marcam o início da estruturação dos processos psíquicos. Por isso a fala aponta para o aparecimento do sujeito do inconsciente" (Campanário, 2008, p. 101). A pulsão invocante desnatura o corpo com a linguagem, abrindo a superfície de inscrição em que um novo falante pode assumir a palavra. Fazendo o audível na voz se perder de uma conformação puramente sonora, coloca-se essa dimensão da perda para que a voz marque o corpo em sua organização significante.

A inscrição, resultante da perda originária, dá andamento ao funcionamento do corpo como pulsionalidade, instituindo uma gramática e perdendo-se, assim, o registro de uma natureza instintual. Nesse sentido, a pulsão é - ela mesma - resultante da desnaturação do corpo pela linguagem. (Jerusalinsky \& Fendrik, 2011, p. 137)

Eleger o bebê como interlocutor o posiciona como alguém possível para a linguagem e abre a malha do simbólico para que ali se construa mais um sujeito. $\mathrm{O}$ manhês, ou esta fala modulada entre agudos e intervalos, introduz sonoramente a alternância entre presença e ausência. Os picos prosódicos da voz convocam e seduzem o bebê, chamam sua atenção, porém se estes picos não são intervalares, alternantes, é como se não houvesse aí, nesse chamado, o espaço para o sujeito se colocar como presente.

Numa estrutura similar à holófrase de significantes, a voz que sonoramente não se altera não admite o espaço para o sujeito se alocar entre suas ondulações. Seja colando os agudos, ou em ausência deles, monotonamente, a voz não remete ao movimento de aparecimento e supressão próprios do inconsciente, ou até mesmo próprios da vida. Induzir cadência, ritmo, modulados pelo som da voz marca a diferença, a heterogeneidade próprias da existência dos significantes.

Pela via da circularidade da pulsão, o sujeito irá atingir a dimensão da falta, também no Outro: os significantes se substituem, mas não se igualam. Entre ida e volta da pulsão, entre a substituiçấo do apelo pela resposta, a heterogeneidade se destaca. Esse intervalo mostra uma hiância. E o que se pode chamar de atividade pulsional é propriamente o fazer-se no lugar dessa hiância. O sujeito reside aí, distingue-se aí, aparece através disso. (Campanário, 2008, pp. 77-78)

A função sonora da voz antecipa a organização discursiva e prepara a 
dimensão significante. Numa dialética a voz opera se destacando como puro som, mas preserva, mantém suas modulações sonoras em sua formação invocante. Os intervalos na prosódia mostram uma hiância, protótipo da estrutura significante em sua versão sonora. Hiância que reserva lugar para um sujeito aí advir.

\section{A lalação}

"De ensaios sonoros o bebê vai progressivamente passando ao exercício da função da fala" (Catão, 2009, p. 220), momento no qual a questão mais premente é que exista um outro que ouça seus barulhos e que, numa função acústica, lhe devolva seus sons como lhe pertencendo, para que, assim, se dê a possibilidade da assunção de sua própria voz. Pela confirmação e resposta da voz do outro a condição enunciativa pode ser assumida formando um endereçamento, ato não apenas comunicativo, mas um endereçamento não anônimo, testemunho da presença de um sujeito do inconsciente.

Consideramos aqui que há um protótipo do estádio do espelho nessa função acústica, que, entretanto, não se faz na assunção da autoimagem, mas sim anteriormente, na assunção dos próprios sons, que constituirão a própria voz. A voz é esse articulador entre o real do corpo e os significantes, antes de se organizar para o infans a dimensão da linguagem. Momento embrionário da função do inconsciente em que algo do sujeito se perfaz com o Outro. Os barulhos emitidos pela criança, assim como o caos sonoro que ela ouve, se organizam como voz, para que em outro tempo a voz possa perder sua dimensão sonora e entrar na dimensão significante organizando-se em palavras, em fala e em linguagem.

Os primeiros balbucios emitidos pela criança despertam a ideia de um diálogo com o manhês, mas a essa réplica na brincadeira fonética não se pode atribuir uma consciência da parte do bebê, ele se dá a esse jogo em pura alienação. A lalação surge como protopalavras em interação com o Outro, essas protopalavras estão "entre um coaxo e um arrulho", é o despertar da língua, momento poético, mítico e criativo, não podendo ser reduzido a qualquer dimensão comunicativa ou intencionada.

Se pensarmos fisiologicamente, no neonato as vias neurais aferentes (que recebem estímulos do mundo externo) estão mielinizadas, já 
as vias eferentes (que conduzem as repostas) não estão mielinizadas (Sanson, 2006), o que nos coloca diante da evidência que a criança está totalmente apta a captar do Outro seus significantes, seus estímulos, sua voz, porém ela própria emite sons aleatórios, rudimentares, primitivos; ensaio vocal em que não há intencionalidade ou pensamento articulado aos sons, é este, pois, um momento de pura criação, do princípio protagonizado pelo verbo.

Relativamente a isso, Lacan pontua que "na origem, o $\mathrm{S}$ não tem nada a comunicar" e acrescenta dizendo que os "instrumentos da comunicação estão do lado do Outro" (Lacan, 2005, p. 296). Portanto, por mais que o bebê pareça querer dizer algo na lalação, não há ainda algo articulado por trás desses sons que ele emite, a atribuição de sentido a essas protopalavras será dada pelo outro no processo que transforma a necessidade em demanda, e é nesse processo que se pressupõe haver um sujeito na criança, pois sem tal pressuposição não haveria a condição necessária para o sujeito aí se formar.

Desconsideramos, assim, qualquer natureza biológica que desperte a criança numa programação instintiva, bem como qualquer princípio metafísico que pressuponha do lado da criança alguma intencionalidade antes mesmo de haverem subsídios psíquicos para isso. Desta maneira, reafirmamos que a linguagem produz uma desnaturação do ser e que o humano, propriamente, se faz nesse destacamento da natureza feito pela cultura e pelos cuidados que são ofertados ao infans, veiculando uma mensagem de pura significância. Essa é a radical dependência do outro que existe nos primeiros tempos da vida, "não basta ter suas necessidades atendidas para que o sujeito nasça; é preciso mais. É preciso que aí tenha um Outro Primordial que tenha prazer com essa satisfação" (Bernardino, 2006, p. 59) e se enderece à criança com seu desejo.

A criança não nasce pronta, tanto seu corpo quanto seu psiquismo dependem radicalmente dos cuidados e do desejo do outro para entrar na ordem da linguagem, o que nos faz dizer que o bebê é sempre prematuro, mesmo quando nascido após 9 meses de gestação: ele é prematuro para a organização humana. Jerusalinsky (2011) se pergunta: "quando nasce um sujeito?" e responde: "Diríamos que nasce em um tempo lógico disjunto ao momento do nascimento biológico, nasce em uma extemporialidade, a criança sempre é extemporânea" (Jerusalinsky \& Fendrik, 2011).

A esse nascimento extemporâneo que a voz convoca como objeto pulsional, a voz comporta tanto uma apropriação de algo 
como a abertura de um vazio, trata-se, portanto, da incorporação de um lugar vazio (Catão, 2011). O destaque do objeto pulsional voz, tanto põe em evidência a organização do som, que se faz pelas modulações linguageiras, quanto abre o espaço do silêncio para além da falta de ruídos. O silêncio como significante e não apenas como ausência de som é condição necessária para a existência da linguagem. Só é possível silêncio após o destacamento da voz como objeto pulsional, comportando em si a dimensão significante a que a pulsão envia.

\section{Um grão de linguagem e o ponto de surdez}

Em O seminário, livro 10: a angústia, 1962-1963, Lacan (2005) toma como imagem a figura da dáfnia, um animal marinho semelhante ao camarão. Esse pequeno ser, em determinado momento da vida, capta de seu ambiente grãos de areia que introduz num aparelho similar a um ouvido rudimentar (o utrículo estato-acústico).

Uma vez introduzida de fora essas partícula de areia, pois o camarão náo as produz sozinho, de modo algum; o utrículo volta a se fechar e eis que o animal passa a ter em seu interior os pequenos guizos necessários a seu equilíbrio, e os quais ele precisou trazer de fora. (Lacan, 2005, p. 301)

O mesmo processo que a dáfnia realiza com o grão de areia, poderíamos dizer que os humanos realizam com a partícula incorpórea da voz. Esta partícula de voz seria o grão mínimo da linguagem, que Lacan (2005) diria não ser assimilada, mas sim incorporada por nós. A voz, como um grão de linguagem, se instala "no ouvido" do infans, vinda do Outro.

Porém, não podemos compreender de forma simplória essa incorporação. Esse grão que se instala - tanto o grão de areia na dáfnia quanto o grão de linguagem no humano - não é um princípio físico que inaugura um movimento depositário sobre o primeiro ponto, essa dinâmica depositária seria mais aproximada da maneira como forma-se a pérola, que, diferentemente, é um elemento sólido, maciço dentro de um corpo.

Esse grão de linguagem do qual falamos se presta a ser elemento rodeado de vazio, sua introdução inaugura um vazio, e poderíamos dizer que, sendo sensível a flutuações, confere a 
possibilidade de equilíbrio ao humano em um ambiente de significantes. Ele então marca a incorporação de um vazio (Catão, 2011) que descompleta o real. A voz que interfere no corpo do infans "faz furo no real" (Lacan, 2007a), real maciço que precisa ser vazado por algo que lhe descomplete.

A voz, ela própria, não pode ser ouvida apenas em sua dimensão de som, dimensão real, ela deve transportar algo do significante, como propõe Catão (2011). O infans deve poder ensurdecer para a dimensão sonora da voz e aceder ao inaudito, isto é, à voz propriamente dita (Catão, 2011). A voz propriamente dita, a que ela se refere, é a voz em sua dimensão significante, que veicula o enigma do desejo do Outro. A voz em sua dimensão sonora convida o infans a fazer parte da linguagem, mas, para se tornar sujeito, é necessário ensurdecer para a dimensão puramente sonora da voz, ascendendo a sua dimensão significante.

O ponto de surdez, então, se mostra como estruturante da linguagem tanto quanto a voz. É o que faz a palavra sair de uma dimensão unívoca, puro som advindo de um Outro completo, para se colocar em uma dimensão equívoca, vinda de um Oui tro descompletado, a quem se poderá articular a questão: "ele me dizi isso, mas o que é que ele quer?’ (Lacan, 2008, p. 209). Essa interrogação sobre o desejo do Outro é um momento paradigmático da constituição psíquica e só poderá se fazer na medida em que houve um ensurdecimento para a o real da voz. 
A voz como puro som expressa uma literalidade que deve ser ultrapassada: "Para tornar-se o primeiro objeto da pulsão, a voz deve ser perdida enquanto puro som. Ela deve passar de som puro à som para, como propõe Poizat, dito de outro modo, endereçada a alguém" (Catão, 2011, p. 27, tradução nossa).

Ou seja, junto com esse grão de voz que se aloca no ouvido da criança deve haver um ponto de surdez, necessário à constituição subjetiva, um vazio, que permita à voz sair da sua natureza de puro som e advir como significante. O ponto de surdez é organizador da linguagem tanto quanto a voz, pois somente a partir do momento que se consegue ignorar a parte puramente sonora da voz e a literalidade dos ditos é que se ascende à dimensão propriamente significante da palavra.

\section{Linguagem: um parasita que se torna órgão}

Usaremos um pouco mais os paralelos metafóricos com a biologia para falar sobre a incorporação da linguagem e a constituição subjetiva no infans. Comparemos, agora, a linguagem a uma bactéria que se instala no interior de um corpo, e que essa ligação caminha de tal forma que o que era um parasita se tornou um órgão para aquele corpo. Este é o processo que ocorreu entre a célula primordial e a mitocôndria.

Como é amplamente sabido, existe a teoria de que a mitocôndria, antes de ter se tornado uma importante organela celular, fora um microrganismo autônomo. Isso se prova pelo fato de que ela possui um DNA próprio que se assemelha ao das bactérias. As hipóteses são que, através da fagocitose, a protocélula englobou a protomitocôndria, ou a protomitocôndria (que era um tipo de proteobactéria) instalou-se no envoltório protocelular, parasitando este organismo, pois ali conseguiria alimento e proteção.

Partimos, então, da ideia de que a linguagem é algo externo ao filhote humano, um corpo estranho que o rodeia. Em algum momento, pode parasitar seu ser, se tornando após certo processo, um órgão adquirido, mas nem por isso menos vital. Esse órgão irá metabolizar o significante. A linguagem é, pois, o órgão responsável pelo metabolismo do significante. 
Lacan reflete baseado numa conversa com Chomsky: "Em suma, a linguagem é, ela mesma, um órgão" (Lacan, 2007a, p. 31), mas jamais poderíamos supor que é um órgão natural, com o qual já nascemos, e que começará a funcionar automaticamente após o nascimento, assim como os pulmões ou o coração. Para dizer da estranheza deste órgão, e de sua inquietante estrageridade, que introduzimos o paralelo com as teorias da mitocôndria. Parece-nos bem rico pensar desta forma tal paradoxo: somos parasitados pela linguagem, porém ela tornou-se vital para nós, assim como nossos órgãos.

Heidegger (1967, p. 24) diz que "a linguagem é a casa do ser. E nessa morada habita o homem", uma imagem muito bonita, porém, na psicanálise, principalmente diante do que é visto através dos fenômenos do autismo e da psicose, pensamos que não habitamos a linguagem, ela que nos habita. Somos habitados por ela e não é raro que essa hospedagem seja conflituosa. Diferentemente da mitocôndria que parasitou a célula, a relação do humano com a linguagem não se tornou uma endossinbiose estável, algo que a clínica nos atesta.

Vê-se que no autismo é essa assunção de um significante e de uma posição enquanto falante que não se faz, ao que compreendemos que deixar-se alienar e que algo alheio lhe habite é o preço que todo falante paga para estar na linguagem. Oferecer-se, oferecer o próprio corpo ao gozo do Outro e à parasitagem dos significantes, seria o terceiro tempo do circuito pulsional. Uma oferta que não comporta uma entrega completa, pois o que a criança oferece ganha sua significância nesse jogo de oferta e recusa. Assim, a criança pequena, em uma dialética, vai reconhecendo o território estrangeiro que o seu corpo representava para ela mesma. "Acrescentamos que a criança se faça comer, se faça olhar, se faça escutar, se faça carregar pela mãe. Ao completar este terceiro tempo do circuito pulsional, aparece um novo sujeito" (Campanário, 2008, p. 70).

Nesse movimento que também comporta a possibilidade da criança se fazer ouvir (o que quer dizer que ela deixa de emitir sons aleatórios e ao léu), ela passa a endereçar-se, a querer chamar a atenção a se fazer de objeto para o desejo do Outro. Como parte da mesma dinâmica, a criança se faz chamar, ela não apenas chama, mas espera que o outro a chame. Em um movimento de alienação, a criança se coloca como objeto do Outro para em outro momento poder separar-se disso, pois a manutenção de uma posição objetal anula a condição desejante.

A alienação e a separação são os operadores derivados da lógica formal, que foram destacados por Jacques Lacan, por serem capazes de nos permitir deduzir as duas operações constituintes do sujeito, ou seja, operaçóes que classificam o sujeito em sua dependência significante ao lugar do outro. (Vorcaro, 1999, p. 23) 
Ser um corpo receptivo à voz do Outro não basta para o metabolismo do significante. Deixar-se alienar ao chamado do outro é apenas um princípio, alienação e separação constituem movimentos intercambiados nos quais sujeito e Outro tramitam com a linguagem nas vias do inconsciente e do desejo. Nesse jogo a voz tem função estruturante e estrutural. A parte real da voz é som e barulho, a voz como objeto pulsional comporta algo de sonoro, mas que se distancia desta dimensão para se colocar em sua função significante. Ela é, ao mesmo tempo, o que chama o infans a advir como sujeito, mas também do que o infans deve se separar para realizar-se como sujeito, o objeto voz deve ser contornado, cavando um lugar que permanece vazio e reenvia o enigma.

A voz como um grão de linguagem que inaugura um vazio tem a potência de resguardar, preservar, acolher a capacidade criativa do enigma e do equívoco, condições para o inconsciente e para a linguagem. Como objeto pulsional, em sua dimensão significante, a voz pode assegurar o inédito e veicular o interdito. A interdição nunca é algo claramente dito em sua literalidade, a própria palavra diz, a interdição é um inter-dito, é algo que a linguagem veicula entre os dizeres, nas entrelinhas, e o inédito é a condição mesma da criação. Haver algo que ainda não foi dito, nem escrito, é o que nos convoca a mais uma vez dizer, a mais uma vez falar e percorrer o caminho de palavras andando entre 
as pedras e as perdas que a própria condição de falantes nos obriga a reconhecer.

A fala é uma organização em que as modulações são próprias de uma cultura, retiradas de uma língua e articuladas por um sujeito, que se anunciam. Falar passa pelo universal da linguagem, atravessa o particular de uma cultura e encontra o singular de um sujeito. $\mathrm{O}$ voto à alteridade se faz na estrutura mesma da assunção do significante, pois, como semente que vem do outro, o significante realiza o sujeito excentricamente, fora de uma referência localizável no ego ou centrada em "si mesmo".

A fala é o ato de um sujeito excêntrico ao enunciado que reúne sua consistência imaginária. Na substituição de significantes que fazem a metáfora e a metonímia, Lacan encontrou o transporte do sujeito sempre alhures ao funcionamento, indefinidamente substitutivo. (Vorcaro, 2004, p. 19)

Consideramos, pois, que a voz é um elemento estrangeiro ao neonato, mas que o cativa. Partindo da ideia de que a linguagem é algo externo ao filhote humano, um corpo estranho, se pudermos brincar com essa palavra, diríamos que a linguagem é quase um alien para o bebê, no sentido que o convoca a se alienar, a ser abduzido, a se tornar alheio a "si mesmo" nos tempos em que esse "si mesmo" era apenas o lugar onde reina um caos pulsional. Algo que inicialmente é um alien (alheio e alienante) para o ser que acabou de nascer, se implanta, então, em seu ser, dependendo de seu consentimento. $O$ processo de constituição psíquica não é algo instintual ou natural, mas uma escolha forçada que se faz num tempo imemorável. No autismo, testemunhamos que parte deste processo de estruturação parece não se dar.

Para o autista, a voz não se destaca como objeto pulsional circunscrevendo uma falta, ela não abre intervalos nos quais, entre significantes, o sujeito pode advir. Algo na convocação do infans ou em seu consentimento em alienar-se parece não proceder, explicitando que o processo de tornar-se falante é de uma complexidade inestimável. Tentamos, então, neste trabalho, elencar alguns pontos que nos parecem pertinentes, nesse trajeto que torna o filhote humano um sujeito da palavra, para com isso angariar recursos para o trabalho clínico.

Colocar a inauguração do falante com algo não automático, mas fruto de um processo, nos dá subsídios para a clínica do autismo na medida em que há algo por se fazer. O som, a voz, a palavra e a fala são instâncias distintas a trabalhar na organização psíquica e a sus-

274 Estilos clin., São Paulo, v. 19, n. 2, mai./ago. 2014, 263-276. 
tentação de um discurso que preserva a capacidade poética, sustentando o enigma, pode colocar no campo do autismo alguma possibilidade da palavra. O silêncio do analista se coloca como um silêncio invocante no qual não apenas há espera, mas sim esperança. "Haveria então uma voz que não fala e, no entanto, toca o sujeito" (Vivès, 2012, p. 24), uma voz áfona que, sustentada pelo desejo, veicula uma mensagem de pura significância abrindo talvez uma superfície de inscriação ao infans.

\section{Abstract \\ AUTISM AND THE BEGINNINGS OF THE WORD: INVOCATORY DRIVE, BODY AND LANGUAGE}

From the enigma posed by autism, this paper analyzes the entering of the baby on language, the vicissitudes of the merger of voice and its operation as a drive object. We consider mom talk and lalation as phenomena in which the function of sound and significant function of voice operate to articulate the encounter between the infans's real body with symbolic language. We postulate that there is not an instinctive or natural order to the advent of language, and that the word is something foreign to the neonate. We consider such elaborations fundamental to direct clinical work with autism.

Index terms: psychoanalysis; autism; language; voice.

\section{RESUMEN}

AUTISMO Y LOS INICIOS DE LA PALABRA: PULSIÓN INVOCANTE, EL CUERPO Y EL LENGUAJE

Partiendo del rompecabezas del autismo, este trabajo analiza la entrada del bebé en el lenguaje, las vicisitudes de la incorpora- ción de la voz y su operación como objeto pulsional. Consideramos el "manhês" y la "lalação" como fenómenos en los cuales las funciones sonora y significante de la voz operan para articular el encuentro entre el real del cuerpo del infans con el simbólico del lenguaje. Planteamos que no hay un orden de entrada instintiva o natural, que la palabra es algo raro al neonato y consideramos tales elaboraciones fundamentales para direccionar el trabajo clínico con el autismo.

Palabras clave: psicoanálisis; autismo; lenguaje; voz.

\section{REFERÊNCIAS}

Bernardino, L. M. F. (2006). A abordagem psicanalítica do desenvolvimento infantil e suas vicissitudes. In L. M. F. Bernadino (Org.), O que a psicanálise pode nos ensinar sobre a criança, sujeito em constitução (pp.19-41). São Paulo: Escuta.

Campanário, I. S. (2008). Espelho, espelho meu: a psicanálise e o tratamento precoce do autismo e outras psicopatologias graves. Salvador, BA: Ágalma.

Catão, I. (2009). O bebê nasce pela boca: voz, sujeito e clínica do autismo. São Paulo: Instituto Langage.

Catão, I. (2011). Du réel du bruit au réel de la voix: la musique de l'inconscient et ses impasses. Revue Insistance, 5, 19-34.

Heidegger, M. (1967). Sobre o humanismo. Rio de Janeiro: Tempo Brasileiro.

Jerusalinsk, A., \& Laznik, M. C. (2011). Uma discussão com a neurociência. In A. Jerusalinsk, \& S. Fendrik (Orgs.), O livro negro da psicopatologia centemporânea. São Paulo: Via lettera.

Jerusalinsky, A., \& Fendrik, S. (Orgs.) (2011). O livro negro da psicopatologia contemporânea. São Paulo: Via Lettera.

Jorge, M. A., \& Ferreira, N. (2005). Lacan, o grande freudiano. Rio de Janeiro: Zahar.

Lacan, J. (2005). O seminário, livro 10: a angústia, 1962-1963. Rio de Janeiro: Zahar. 
Lacan, J. (2007a). O seminário, livro 23: o sinthoma, 1975-1976. Rio de Janeiro: Zahar.

Lacan, J. (2008). O seminário, livro 11: os quatro conceitos fundamentais da psicanálise 1964. Rio de Janeiro: Zahar.

Laznik, M. C., Maestro, S., Muratori, F., \& Parlato-Oliveira, E. (2006). Interaçóes sonoras entre bebês que se tornaram autistas e seus pais. In L. M. F. Bernardino (Org.), O que a psicanálise pode nos ensinar sobre a criança, sujeito em constituição (pp. 95-106). São Paulo: Escuta.

Laznik, M. C. (2004). A voz da sereia. Salvador, BA: Ágalma.

Sanson, J. C. (2006). Mais uma vez, as inscriçôes primordiais. In L. M. F. Bernardino (Org.), O que a psicanálise pode nos ensinar sobre a criança, sujeito em constitição (pp. 56-66). São Paulo: Escuta. Vivès, J. M. (2012). A voz na clínica psicanalítica. Rio de Janeiro: Contra Capa.

Vorcaro, A. M. (1999). Crianças na psicanálise: clínica, instituiçâo, laço social. Rio de Janeiro: Companhia de Freud.

Vorcaro, A. M. (2004). A criança na clínica psicanalítica. Rio de Janeiro: Companhia de Freud.

\section{NOTA}

1. Manhês remete à palavra mãe, à função maternante, porém é importante marcar que a função materna pode ser desempenhada por qualquer sujeito falante, não apenas uma mulher que gerou uma criança pode exercer a função de mãe, e que, o manhês ganha certa independência da funçáo materna, em alguns casos, como a clínica nos atesta. "Interessante observar que em inglês se diz também, parêntese e não apenas motherese, o que parece mas justo, pois os pais e também tios e avós falam com o bebê nessa entonaçáa” (Laznik, Maestro, Muratori \& Parlato-Oliveira, 2006).

alinetravaglia@hotmail.com

Rua Vanderlei, 331

05011-000 - São Paulo - SP - Brasil.

Recebido em agosto/2013. Aceito em janeiro/2014.

276 Estilos clin., São Paulo, v. 19, n. 2, mai./ago. 2014, 263-276. 